\title{
Rhizobia Modulate Root-Hair-Specific Expression of Extensin Genes
}

\author{
Ivana Arsenijevic-Maksimovic, William J. Broughton, and Andrea Krause \\ L.B.M.P.S., Université de Genève, 1, ch. de I'Impératrice, 1292 Chambésy/Genève, Switzerland \\ Received 22 April 1996. Accepted 30 October 1996.
}

\begin{abstract}
Three cDNAs (ext3, ext127, and ext26), originally isolated by differential screening from a root-hair cDNA library of Vigna unguiculata, were found to encode extensin-like cell wall proteins. Transcripts homologous to these cDNAs were only detected in root hairs where mRNA levels decreased 1 day after inoculation with rhizobia. This coincided with the onset of root-hair deformation, the first morphological step in the Rhizobium-legume interaction. Decreases in transcript levels following inoculation with wild-type Rhizobium sp. NGR234 were more pronounced than with NGR $\triangle$ nod $A B C$, a mutant deficient in Nod-factor production. Inoculation with a rhizobial strain carrying a mutation in a gene encoding a transcriptional activator for nod genes (NGR $\Delta$ nodD1) did not repress mRNA levels, indicating that a second nodulation signal may be present that is nodD dependent. Application of purified NodNGR factors only affected transcript levels of ext3. The genomic locus of the gene homologous to ext26 (Ext26G) was cloned. In the 5' flanking region, several potential TATA boxes and CAP signals were identified. Part of the promoter region shares homology with the Pisum sativum seed lectin promoter and the Nicotiana tabacum nitrate reductase promoter region. Nonetheless, the function of these homologous regions in gene regulation is unknown.
\end{abstract}

Additional keyword: symbiosis.

Root hairs are unicellular extensions of root epidermal cells that develop near the root apex. They emerge at the apical end of certain epidermal cells and elongate by polar growth of the tip (Cormack 1962), which has high exocytotic and cell wall assembly activities (Ridge 1988). Root hairs can be extensively colonized by soilborne microbes, including nitrogenfixing bacteria such as Rhizobium. Young, growing root hairs play an important role in symbiotic recognition, and they are the main entry points for rhizobial infection (Dart 1977). To penetrate into the hosts via root hairs, rhizobia stimulate and reorientate the growth of root-hair cell walls (Kijne 1992) re-

Corresponding author: Andrea Krause; Tel: 41-22-7320420; Fax: 41-227320734; Email: Krause@ sc2a.unige.ch

Present address of Ivana Arsenijević-Maksimović: Faculty of Agriculture, University of Novi Sad, 21000 Novi Sad, Yugoslavia.

Nucleotide sequence data reported in this paper is to be found at EMBL, GenBank, and DDBJ data bases as accession number X91836. sulting in deformed (Had) and curled (Hac) root hairs. Within these curled root hairs, rhizobia promote the formation of infection threads through which they enter the plant. This leads to the development of a completely new plant organ, the nodule.

The interaction is set in motion when rhizobia are attracted by plant-secreted flavonoids (Fellay et al. 1995). Specific flavonoids then interact with the rhizobial NodD protein, which becomes a positive transcriptional activator of other nod genes (Schultze et al. 1994). The latter encode proteins playing a crucial role in the biosynthesis of Nod factors that, in turn, are recognized by the plant and induce various symbiosis-related responses, such as root-hair deformation and curling (Relić et al. 1994). Synthesis of the basic Nod-factor structure is catalyzed by the NodABC proteins, which are common to all rhizobia. The other Nod proteins are involved in the addition of various substituents that render the Nod factor host-specific (Fellay et al. 1995).

Genetic mechanisms involved in initiation of the plant response to rhizobia are poorly understood, although a few plant genes whose expression is specifically modulated by rhizobia or its Nod factors have been identified (Franssen et al. 1995; Schultze et al. 1994). Genes encoding proteins involved in root-hair responses are called hadulins (Krause and Broughton 1992), while those participating in nodule morphogenesis are named early nodulin genes (Franssen et al. 1992). Krause and Broughton (1992) identified 12 Rhizobium-induced proteins associated with root-hair deformation in Vigna unguiculata, of which three are hadulins. One of the hadulin genes encodes a lipid-transfer-like protein that might play a role in the transport of Nod factors (Krause et al. 1994). Many of the genes characterized so far seem to code for structural cell wall proteins, possibly indicating that the cell wall of the developing nodule is different from the root.

To examine the mechanism of root-hair deformation, we constructed a cDNA library from $V$. unguiculata root hairs isolated after inoculation with Rhizobium sp. NGR234 (Krause et al. 1994). Differential screening and probing with heterologous sequences permitted isolation of cDNA clones homologous to genes encoding extensins (ext3, ext127, and ext26), a class of structural cell wall proteins (ArsenijevićMaksimović et al. 1995). Here, we describe the expression of these genes in different tissues as well as their regulation by rhizobia. The genomic locus corresponding to one of these genes was also isolated and partially characterized. 


\section{RESULTS}

\section{Expression analyses.}

To test for the presence of mRNAs corresponding to ext3, ext26, and ext 127 in different plant tissues, consecutive Northern (RNA) blot analyses were performed on one set of membranes with the three different cDNA clones as probes (Fig. 1). Transcripts of all three genes were only detected in root hairs. Differences in the size of the transcripts confirmed

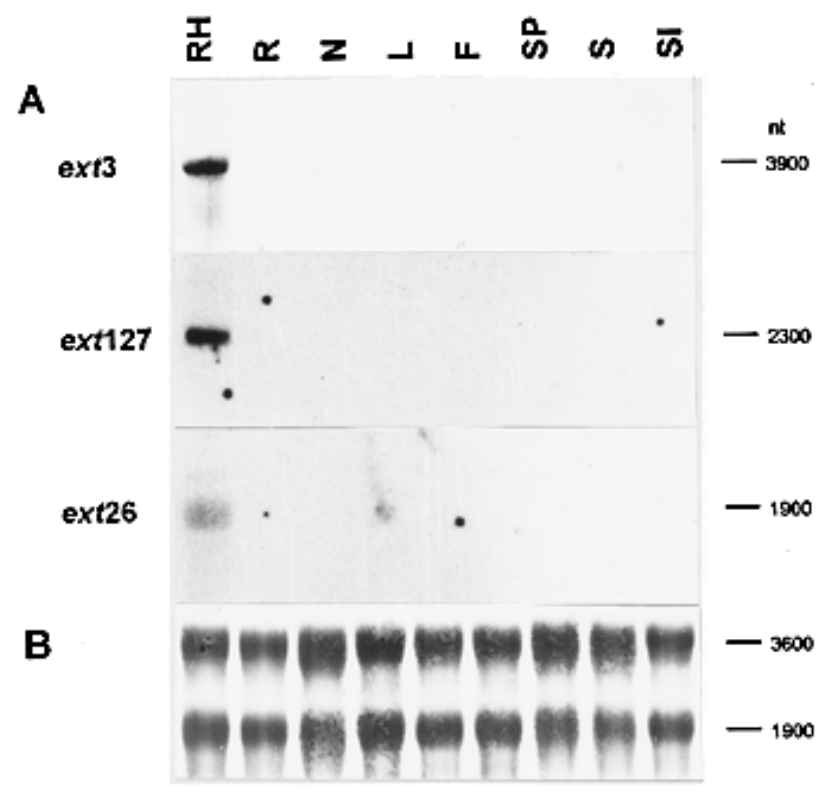

Fig. 1. Differential expression of genes encoding extensins in various tissues of Vigna unguiculata. Total RNA $(10 \mu \mathrm{g})$ was extracted from root hairs $(\mathrm{RH})$, roots $(\mathrm{R})$, nodules $(\mathrm{N})$, leaves $(\mathrm{L})$, flowers $(\mathrm{F})$, seed pods (SP), seeds (S), and seedlings (SI). A, Hybridization against different cDNAs. B, Amounts and integrity of ribosomal RNA were confirmed by staining the filter with methylene blue.

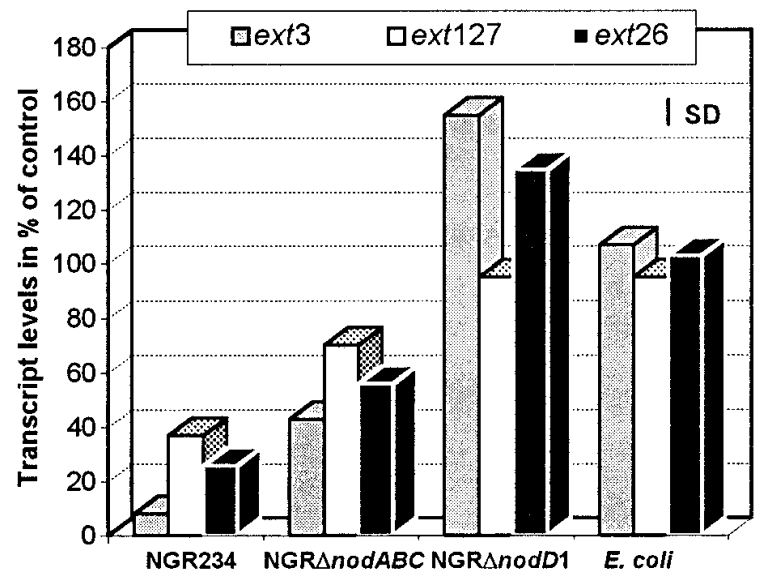

Fig. 2. Differential expression of genes corresponding to ext3, ext 127 , and ext 26 in root hairs 1 day after inoculation with Rhizobium sp. NGR234 (NGR234), Rhizobium sp. NGRAnodABC (NGR $\Delta$ nodABC), Rhizobium sp. NGRAnodD1 (NGRAnodD1), and Escherichia coli XL1Blue. Sterile water was sprayed on seedlings as a control. Amounts of transcripts were estimated by densitometry and corrected for loading differences. that ext 3 , ext 127 , and ext 26 correspond to different genes in $V$. unguiculata, as assumed from sequence analyses (ArsenijevićMaksimović et al. 1995).

To examine whether rhizobia effect expression of genes encoding extensins, mRNA levels were also determined in root hairs 1 day after inoculation with Rhizobium sp. NGR234, NGR $\triangle$ nod $A B C$, and NGR $\Delta$ nodD1. Densitometric analysis of hybridization signals demonstrated that the amounts of transcripts corresponding to ext 3 were reduced to $8 \%$, to ext 127 to $30 \%$, and to ext 26 to $26 \%$ of control levels following inoculation with the wild-type rhizobia NGR234 (Fig. 2). Surprisingly, inoculation with NGR $\triangle \operatorname{nod} A B C$, a strain unable to synthesize Nod factors, also reduced (albeit less dramatically) levels of all three transcripts (to 43\% [ext3], to 75\% [ext127], or to $56 \%$ [ext26]). In contrast, inoculation with NGR $\Delta n o d D 1$, a mutant blocked in the synthesis of the positive transcriptional regulator for nod genes and therefore unable to synthesize Nod factors, increased mRNA levels corresponding to ext 3 and ext 26 to 155 and $135 \%$, respectively, while those corresponding to ext 127 were not significantly changed. Escherichia coli, like NGR234 and its mutant strains, also attaches to legume roots, but it is unable to penetrate them. Nonetheless, treatment with $E$. coli had little effect on the amounts of mRNAs encoding extensins (Fig. 2).

Since the difference in transcript levels observed after inoculation with NGR234, compared with NGR $\triangle$ nodABC, could be due to Nod factors, we tested whether a decrease in levels of extensin transcripts could be induced by their application. mRNA levels were determined 1 day after treatment with concentrations of Nod factors sufficient to induce roothair deformation and curling in the spraying system used here (concentrations lower than $10^{-7} \mathrm{M}$ had no effect on root-hair deformation and curling). Both $10^{-7} \mathrm{M}$ and $5 \times 10^{-6} \mathrm{M}$ NodNGR[Ac] factors reduced levels of ext3 transcripts to 50 and $58 \%$, respectively, of the control values (Fig. 3). Surprisingly, $10^{-7} \mathrm{M}$ NodNGR factors had no effect on the amounts of transcripts homologous to ext 127 and ext 26 . Higher concentrations $\left(5 \times 10^{-6} \mathrm{M}\right)$ increased the amounts of transcripts to 130 and $115 \%$, respectively (ext26 and ext127).

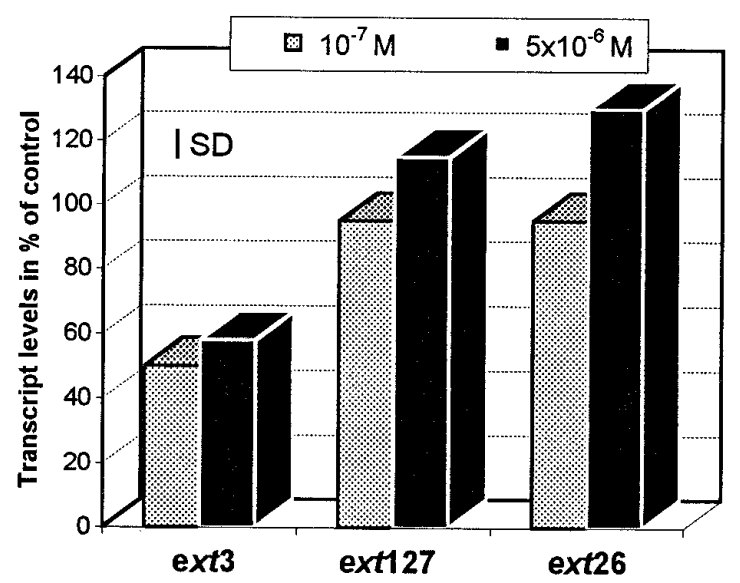

Fig. 3. Histogram showing the relative amounts of extensin transcripts in root hairs following treatment with Nod factors. Root hairs were isolated from seedlings 1 day after treatment with purified, acetylated NodNGR-factors. As a control, sterile water was sprayed on seedlings. Amounts of transcripts were determined by densitometric analysis and corrected for loading differences. 


\section{Organization of genes encoding extensin-like proteins in V. unguiculata.}

Genomic DNA of $V$. unguiculata was digested with various restriction enzymes and probed with ext 3 under standard conditions. Multiple hybridization signals for each restriction digest showed that numerous loci in the genome of $V$. unguiculata are homologous to ext3 (data not shown). Hybridizations of Southern blots of genomic DNA with ext 3 , ext 127 , and ext 26 as probes under conditions of increased stringency resulted in three clearly different restriction patterns (Fig. 4). Variation in the hybridization patterns confirmed that ext 3 , ext 26 , and ext 127 correspond to different plant genes. ext 127 and ext 26 hybridized to a single band of DNA formed after digestion with various restriction enzymes, indicating that only one copy of these genes is present in the genome. ext 3 , in contrast, is most probably present in two copies.

\section{Isolation and characterization of the genomic locus corresponding to ext 26 .}

To see if expression of extensins by rhizobia is regulated by previously characterized promoter elements, the genomic locus of one of the genes encoding a root-hair-specific extensin was isolated. Screening of $5 \times 10^{5}$ recombinant phages from a genomic library of $V$. unguiculata DNA under conditions of high stringency with ext 26 revealed nine positive clones. DNA of three phages (G2, G19, and G20) was sequenced with a primer sequence specific to the untranslated, nonrepetitive $3^{\prime}$ part of ext26. The sequence of all three phages was identical to ext 26, showing that they contain at least a part of the corresponding genomic locus. Restriction enzyme and Southern transfer analysis showed that G2 and G20 display hybridization patterns identical to that of $V$. unguiculata genomic DNA. The insert from phage G2 was chosen for further analysis and named Ext26G.

The nucleotide sequence of Ext26G starts with a $5^{\prime}$ untranscribed leader (Fig. 5). Computer scans for eukaryotic promoter elements showed that there are several potential minimal promoter elements (TATA boxes and CAP signals). Those with the highest probabilities are located from positions -139 to -125 and from -77 to -63 (TATA boxes), as well as from -100 to -94 and from -31 to -25 (CAP signals), relative to the first methionine residue. All parts of the sequence analyzed were within the cut-off value for GC and CAAT boxes. Eucaryotic Promoter Database (EPD) searches showed that Ext $26 \mathrm{G}$ shares $70 \%$ identity with parts of a promoter region of the Pisum sativum seed lectin gene (Gatehouse et al. 1987). This identity is located from bp -38 to 13 , and includes one of the putative CAP signals. Ext26G also shares homology $(83 \%$ between positions -132 and -161) with a part of the Nicotiana tabacum nitrate reductase promoter region (Vaucheret et al. 1989). Other promoter elements, such as those involved in regulation of extensin-encoding genes (Granell et al. 1992; Holdsworth and Laties 1989) were not found in Ext26G.

There are two putative translation start sites, separated by $51 \mathrm{bp}$ (Fig. 5). Each shares the same degree of homology with the plant consensus sequence (Messing et al. 1983). The deduced protein sequence of the genomic locus consists of 489 amino acid (aa) residues with a predicted molecular mass of $53,896 \mathrm{Da}$ and an estimated isoelectric point (pI) of 9.7. Hydropathy analysis of the amino acid sequence underlines the repetitive nature of the protein and indicates that the protein is slightly hydrophilic except for the N-terminal end (Fig. 6). This hydrophobic segment contains a sequence characteristic of trans-membrane helixes, and is positioned from aa 9 to 24 (LILAFAICLMAITVAA), relative to the first putative translation start site (Fig. 5). According to the von Heijne (1986) rules, a potential protein cleavage site exists between aa 23 and 24. The glycine residue at position 32 is a potential $\mathrm{N}$ myristylation site (Fig. 5). At the deduced amino acid level, the clone displayed the repetitive motif $\mathrm{KSP}_{4} \mathrm{SPSP}_{4} \mathrm{Y}_{3}$, which is typical of extensins. It starts after the signal peptide at aa 55 and appears 26 times in the coding region. Only the first unit shows variation $\left(\mathrm{KSP}_{4} \mathrm{SPSP}_{5} \mathrm{YV}\right)$. The first and second repetitive units are separated by an octapeptide $\mathrm{HKYP}_{2} \mathrm{Y}_{3}$, while the other units follow each other directly. In several repetitive units, the middle tyrosine residue is replaced by valine (see also Figure 6), and in the last one, the third tyrosine residue is replaced by proline. There is no repetitive motif in the last 11 aa of the coding region, but a block of 4 proline residues is present (Fig. 5). A putative polyadenylation signal (also present in the cDNA) is situated at bp 1507 to 1512 . Ext26G contains no intron sequences, as is common in genes encoding structural cell wall proteins (Cassab and Varner 1988).

Data base homology searches revealed high similarities of the coding region and the deduced protein sequence of Ext26G with extensin cDNA clones, genes, and proteins from different plants. The highest overall identity, at both the nu-

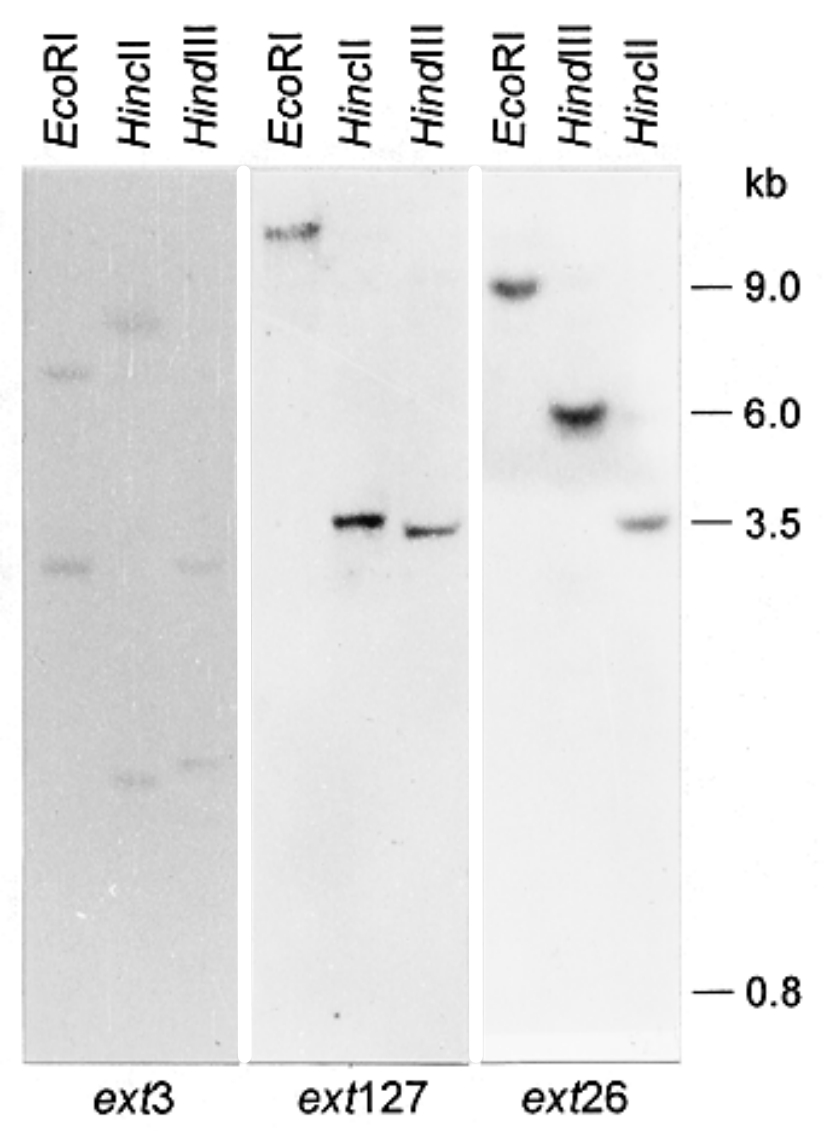

Fig. 4. Southern blot hybridization of total DNA $(10 \mu \mathrm{g})$ from Vigna unguiculata digested with three different restriction enzymes and probed against the cDNAs. 
A -1761

AGCTTACCAACAAAAGTGTGAACGTATGGGCAAGGAAATCTAGCAAATTGGGCCACGATGGCTTACTCACAATTCAGAAA -1681 AACAGTGTTTTTCCGCACGATATATGTCAAAGAAAGTCTTCAAAAATGACCTGGATACAGTGCACAGAACAACGTGCCAA -1601 GCTAATTAATTTAGCTTTGGACAGATATAGAATCATATATTTATGTCGCAAATTCAAAGAAAATCAAAGTGAACTATATG -1521 ATTATGCAATAATTATTTTGGCCAGTGAAAAAGGACAAATTCCATGTCAAACAAATATGCATGTATATATATTTGTACAG -1441 CGGCTTTATTGGGATGAAAAAGTTCTTCGCAAAATAGTATATATTATATTATTATGCATGATTTTCCAATCAACAAAGAA -1361 AAATAAATACACAAGTTGAGAGAAAAACGTATTAGGAAATTGTTCTTCAGACCATTTACCTTCAATGCTGATCTTTCCAT -1281 TTGTGACAGAAACTTTGTACCATGTCTAAGTAACTAAAAAATTAACTGTGTCATGAATTCGCTGAACAATAATATGTAAA -1201 TCGAATCAAATGGGTGGTAATAGAAGATTACAACCGGGATTAATTTTTAATTAATTTGATGAAATTTGGAGAGAGAAAAT -1121 CGCGAAAAATGAATTATCTGGTAGTTAAAGAGACTAATCAGATTAACTTAAGACGTGCATCGATCAAGCAAGAAACGTGT -1041 TAATCAAAGTATTTTTATTGCCTTGATGTATCAAATCAAATAAACAATACGTTGCTCTAACAGAAAAATTAAACAATGCA -961 TTAAATAATAATAATTGAACGATCAATCTAAATTAAAGAAATAAATAGCATTACAACATATCTTCCGAAAATCGATCAAA -881 ATTTCGCCGCCTAGACTTTTTCTTTAATTAGGATATATACATCAGCTTTCAAACTCGCAAATTCATTTACAGCAAATTCA -801 TTTACAGCTTTCAAGTTAAAAAAAAAAAAATCCAGTTGCAGGGTGGAATTGATCAAAGAATCTGTCGGAACAAAATTCTC -721 TGGTGGTGAAAAAAAAAGGCATAAGGTATACACACGTGATGTTGATTAAAACAAACAAAGTAGGTTTACCGGCATAAAAA -641 GTAATTATACCGAGTCAAAAAAACAATTTTTTTAAGTACGAGTTAACGTTTGTCAAGTACGTTAGTTTGATAATACCAAG -561 AAAACATGTCTTGTAACCTGAAGCAGTTTTCACCGACGATAAAAGCATAATTTGAAGAGCAACAAGATAACAAAGATAAG -481 CTCATGTTTTTATAATCCGGAAACATGGCATTATTATTAGGAAGAAAGAAGTGAGGCTAATGATAAAGAAAGACATATTA -401 GAGAATTGCAGGAAGTGATATTGCATTTGACTTTATCATCTGTTTCACACTCCAGGAATTAGTTCTTGGTGAAAAGACAA -321 AGGAAATAATCAGTTTGTCTGCTGTGACGACGCGCTTCTATATATATTTGTTTAAATGTAACGGGAGCTCATTCAACCAC -241 GCCATCACCTACTCTCTTCTTGACTTTGTTCACACCATCCTCAGGAAAATATGAAATCGTTTAATGGCAAACCATAACAt -161 caacttgaatgttaaa ta totatatatGCCAGTGTGTCATCAAACAAAGATATCCTACCAGCCATCACTGAACCTAAA CACTATATAAACCCTTCAAATCAATACTTTGGAAACCAAGAAagtaaaacataatagaaagttttcacattcaaagaag atgggaacgaggCAATGGCCTCGTTTGATCCTTGCATTCGCAATTTGCCTTATGGCTATCACTGTTGCTGCTGATGATTA

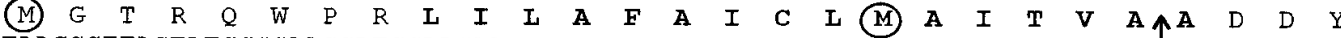
TAAGCCTTACTATGGCCAACCATGGAACAACTATCCAAAACAAACACCTCCTTATTATTACAACGCACCTCCATATTACT $\begin{array}{llllllllllllllllllllllllllll}K & \mathrm{P} & \mathrm{Y} & \mathrm{Y} & G & \mathrm{Q} & \mathrm{P} & \mathrm{W} & \mathrm{N} & \mathrm{N} & \mathrm{Y} & \mathrm{P} & \mathrm{K} & \mathrm{Q} & \mathrm{T} & \mathrm{P} & \mathrm{P} & \mathrm{Y} & \mathrm{Y} & \mathrm{Y} & \mathrm{N} & \mathrm{A} & \mathrm{P} & \mathrm{P} & \mathrm{Y} & \mathrm{Y}\end{array}$ ACAAATCGCCACCTCCACCTTCTCCATCACCACCACCTCCTCCATATGTGCATAAATACCCACCATACTATTACAAATCA \begin{tabular}{llllllllllllllllllllllllllllllll}
$Y$ & $K$ & $S$ & $P$ & $P$ & $P$ & $P$ & $S$ & $P$ & $S$ & $P$ & $P$ & $P$ & $P$ & $P$ & $Y$ & $V$ & $H$ & $K$ & $Y$ & $P$ & $P$ & $Y$ & $Y$ & $Y$ & $K$ & $S$ \\
\hline
\end{tabular} CCTCCACCTCCATCTCCTTCTCCACCTCCTCCATATGTCTATAAGTCACCACCACCACCTTCTCCATCACCACCTCCTC $\begin{array}{llllllllllllllllllllllllllll}\mathrm{P} & \mathrm{P} & \mathrm{P} & \mathrm{P} & \mathrm{S} & \mathrm{P} & \mathrm{S} & \mathrm{P} & \mathrm{P} & \mathrm{P} & \mathrm{P} & \mathrm{Y} & \mathrm{V} & \mathrm{Y} & \mathrm{K} & \mathrm{S} & \mathrm{P} & \mathrm{P} & \mathrm{P} & \mathrm{P} & \mathrm{S} & \mathrm{P} & \mathrm{S} & \mathrm{P} & \mathrm{P} & \mathrm{P} & \mathrm{P}\end{array}$ ATACTACTATAAGTCTCCACCCCCACCATCACCTTCCCCTC CTCCTCCGTATTACTACAAGTCTCCACCACCACCATCTC $\begin{array}{llllllllllllllllllllllllllll}Y & Y & Y & K & S & P & P & P & P & S & P & S & P & P & P & P & Y & Y & Y & K & S & P & P & P & P & S\end{array}$ CCTCACCTCCTCCTCCGTACTACTACAAGTCTCCACCACCACCATCTCCCTCACCTCCCCACCATATGTCTATAAGTCTA \begin{tabular}{llllllllllllllllllllllllllllll}
$P$ & $S$ & $P$ & $P$ & $P$ & $P$ & $Y$ & $Y$ & $Y$ & $K$ & S & P & P & P & P & S & P & S & P & P & P & P & Y & V & Y & $K$ & $S$ \\
\hline
\end{tabular} CCACCACCACCATCCCCATCTCCAC CTCCTCCATATTACTACAAGTCCCCACCACCACCATCTCCTTCACCTCCACCAC $\begin{array}{llllllllllllllllllllllllllll}P & P & P & P & S & P & S & P & P & P & P & Y & Y & Y & K & S & P & P & P & P & S & P & S & P & P & P & P\end{array}$ GTATTACTATAAGTCTCCACCTCCACCTTCACCATCACCTC TCCTCCATATTACTATAAGTCACCACCACCTCCATCTC $\begin{array}{lllllllllllllllllllllllllll}Y & Y & Y & K & S & P & P & P & P & S & P & S & P & P & P & P & Y & Y & Y & K & S & P & P & P & P & S\end{array}$ CATCACCTCCTCCTCCATACGTCTACAAGTCACCACCACCTCCATCCCCGTCACCACCTCCTCCATACTATTACAAGTCC \begin{tabular}{lllllllllllllllllllllllllll}
$P$ & $S$ & $P$ & $P$ & $P$ & $P$ & $Y$ & $V$ & $Y$ & $K$ & $S$ & $P$ & $P$ & $P$ & $P$ & $S$ & $P$ & $S$ & $P$ & $P$ & $P$ & $P$ & $Y$ & $Y$ & $Y$ & $K$ & $S$ \\
\hline
\end{tabular}

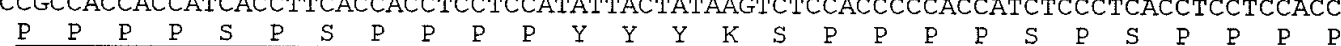
ATACTACTATAAATCACCACCACCTCCATCCCCGTCACCTC TCCTCCATATTACTACAAATCTCCACCCCCACCCTCTC

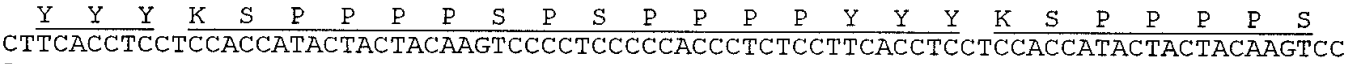
\begin{tabular}{llllllllllllllllllllllllllllll}
$P$ & $S$ & $P$ & $P$ & $P$ & $P$ & $Y$ & $Y$ & $Y$ & $K$ & $S$ & $P$ & $P$ & $P$ & $P$ & $S$ & $P$ & $S$ & $P$ & $P$ & $P$ & $P$ & $Y$ & $Y$ & $Y$ & $K$ & $S$ \\
\hline
\end{tabular} CCACCTCCACCATCACCTICACCAC CTCCTCCATATTACTACAAATCCCCACCACCACCATCTCCCTCACCTCCTCCACC $\begin{array}{llllllllllllllllllllllllllll}\mathrm{P} & \mathrm{P} & \mathrm{P} & \mathrm{P} & \mathrm{S} & \mathrm{P} & \mathrm{S} & \mathrm{P} & \mathrm{P} & \mathrm{P} & \mathrm{P} & \mathrm{Y} & \mathrm{Y} & \mathrm{Y} & \mathrm{K} & \mathrm{S} & \mathrm{P} & \mathrm{P} & \mathrm{P} & \mathrm{P} & \mathrm{S} & \mathrm{P} & \mathrm{S} & \mathrm{P} & \mathrm{P} & \mathrm{P} & \mathrm{P}\end{array}$ ATATGTATATAAGTCCCCACCACCTCCATCTCCATCACCTCCTCCTCCATACTACTACAAGTCCCCGCCCCCACCATCAC $\begin{array}{llllllllllllllllllllllllllll}Y & V & Y & K & S & P & P & P & P & S & P & S & P & P & P & P & Y & Y & Y & K & S & P & P & P & P & S\end{array}$ CTTCACCAC CTCCTCCGTATTACTACAAGTCTCCACCCCCACCTTCTCCCTCACCTC CTCCTCCATACTACTACAAGTCC \begin{tabular}{lllllllllllllllllllllllllll}
$\mathrm{P}$ & $\mathrm{S}$ & $\mathrm{P}$ & $\mathrm{P}$ & $\mathrm{P}$ & $\mathrm{P}$ & $\mathrm{Y}$ & $\mathrm{Y}$ & $\mathrm{Y}$ & $\mathrm{K}$ & $\mathrm{S}$ & $\mathrm{P}$ & $\mathrm{P}$ & $\mathrm{P}$ & $\mathrm{P}$ & $\mathrm{S}$ & $\mathrm{P}$ & $\mathrm{S}$ & $\mathrm{P}$ & $\mathrm{P}$ & $\mathrm{P}$ & $\mathrm{P}$ & $\mathrm{Y}$ & $\mathrm{Y}$ & $\mathrm{Y}$ & $\mathrm{K}$ & $\mathrm{S}$ \\
\hline
\end{tabular} \begin{tabular}{lllllllllllllllllllllllllllll}
$\mathrm{P}$ & $\mathrm{P}$ & $\mathrm{P}$ & $\mathrm{P}$ & $\mathrm{S}$ & $\mathrm{P}$ & $\mathrm{S}$ & $\mathrm{P}$ & $\mathrm{P}$ & $\mathrm{P}$ & $\mathrm{P}$ & $\mathrm{Y}$ & $\mathrm{Y}$ & $\mathrm{Y}$ & $\mathrm{K}$ & $\mathrm{S}$ & $\mathrm{P}$ & $\mathrm{P}$ & $\mathrm{P}$ & $\mathrm{P}$ & $\mathrm{S}$ & $\mathrm{P}$ & $\mathrm{S}$ & $\mathrm{P}$ & $\mathrm{P}$ & $\mathrm{P}$ & $\mathrm{P}$ \\
\hline
\end{tabular} ATACGTATATAAGTCTCCCCCTCCACCTTCTCCGTCACCTCCTCCACCATATTACTACAAATCACCTCCTCCACCGTCTC \begin{tabular}{lllllllllllllllllllllllllll}
$Y$ & $V$ & $Y$ & $K$ & $S$ & $P$ & $P$ & $P$ & $P$ & $S$ & $P$ & $S$ & $P$ & $P$ & $P$ & $P$ & $Y$ & $Y$ & $Y$ & $K$ & $S$ & $P$ & $P$ & $P$ & $P$ & $S$ \\
\hline
\end{tabular} CTTCTCCGC CTCACCATATTATTACAAGTCTCCACCTCCCCCTTCTCCTTCTCCTCCTCCACCATACTACCCCTACCTC $\begin{array}{llllllllllllllllllllllllllllll}\mathrm{P} & \mathrm{S} & \mathrm{P} & \mathrm{P} & \mathrm{P} & \mathrm{P} & \mathrm{Y} & \mathrm{Y} & \mathrm{Y} & \mathrm{K} & \mathrm{S} & \mathrm{P} & \mathrm{P} & \mathrm{P} & \mathrm{P} & \mathrm{S} & \mathrm{P} & \mathrm{S} & \mathrm{P} & \mathrm{P} & \mathrm{P} & \mathrm{P} & \mathrm{Y} & \mathrm{Y} & \mathrm{P} & \mathrm{Y} & \mathrm{L}\end{array}$ TATAACTCACCCCCGCCTCCCGCGTATTAAGCTTCTGGCTAAATCATAATTTGATTTTTTTTTTCCAATAAATCACGTTG $\begin{array}{lllllllllll}Y & N & S & P & P & P & P & A & Y & *\end{array}$ AACATTGTTGCAGTTGTTTTGTAATACTCATTCATTAATAATAGGGTCTACACTGAAGTGGGAGTTGTATTCTGACTGC AGTGTAGCCCATGCGTTTGTATTGGTTTTAATCGAGAAGTGTGTAATATTATTCTCTTCTTATAAATATACATTATTACC ACAGATGTTGGATTCCATTTCCTCTTTTCATTATGAAATTACGATCGCCATGAAATTCACGAATCAGTGCCTCAAAATGC TAAATAACATTTAGATTTGGGAAAAAAAATAGATGAAATGATATTATATTATCTTTTCTAGATGGTTTTAAATAACCAGA AATTAAAA

$-81$

Fig. 5. Nucleotide and derived amino acid sequence of Ext26G. The part of the sequence homologous to the Nicotiana tabacum nitrate reductase promoter region is shown in lower-case italic letters; the part homologous to the Pisum sativum seed lectin promoter region is shown in lower-case bold letters; putative TATA boxes are boxed; putative CAP signals are underlined in bold; putative translation start sites are circled; amino acids constituting putative trans-membrane helices are marked in bold; the putative protein cleavage site is shown with an arrowhead; the glycine residue that might be myristylated is marked in bold italics; repetitive motifs are underlined; a putative stop codon (TAA) is marked by an asterisk; a putative polyadenylation signal (AATAAA) is double underlined. 
cleotide and amino acid levels, is with a hydroxyproline-rich glycoprotein precursor, PVU18791, from P. vulgaris (Corbin et al. 1987; Wycoff et al. 1995). Within the coding regions, the two clones share $75 \%$ (DNA) and $80 \%$ (amino acid) similarity.

\section{DISCUSSION}

ext3, ext26, and ext127 were isolated from a root-hair cDNA library of $V$. unguiculata by differential screening and a heterologous probe (Arsenijević-Maksimović et al. 1995). These clones encode extensin-like proteins, a class of structural hydroxyproline-rich glycoproteins of the plant extracellular matrix. Here we demonstrate that transcripts corresponding to these cDNAs can only be detected in root hairs of V. unguiculata. Many others (e.g., Chen et al. 1993; Goldman et al. 1992; Ruiz-Avila et al. 1992; Smallwood et al. 1994; Ye and Varner 1991) have shown that proline-rich proteins are synthesized in cell-type-, tissue-, or organ-specific ways. To the best of our knowledge, this is the first report of root-hairspecific expression of extensins.

The genomic locus of one of these cDNAs, ext26, was isolated and compared with other loci encoding extensins. Ext $26 \mathrm{G}$ encodes a protein with a putative signal peptide sequence, as is common in many genomic and cDNA sequences encoding extensins. As shown by hydropathy analysis, the signal peptide contains a potential membrane-helix domain. This suggests that Ext26G enters the secretory pathway and that it is targeted to the extracellular matrix (Rost and Sander 1993, 1994). Furthermore, Ext26G encodes an extensin with a dominant, highly conserved type of repeated amino acid unit $\left(\mathrm{KSP}_{4} \mathrm{SPSP}_{4} \mathrm{Y}_{3}\right)$ that is even more regular in structure than that of D. carota and L. esculentum (Showalter et al. 1992).

Hydroxyproline-rich glycoproteins include extensins, repetitive proline-rich proteins, some nodulins, arabinogaloctan proteins, and lectins (Kieliszewski and Lamport 1994). The role of these proteins in cell wall self-assembly lies in their structure, which is dependent on extensive post-translational modifications. These modifications include hydroxylation, glycosylation, and cross-linking. If one assumes that the serine-hydroxyproline repeats of Ext26 might be arabinosylated, this would contribute to molecular inflexibility, as suggested by Kieliszewski and Lamport (1994). YXYK (where X represents any amino acid) peptide stretches (of which Y3K is typical of Ext26G) play a role in formation of intra-molecular isodityrosine (IDT) cross-links that increase molecular rigidity and hydrophobicity. Thus, Ext26G may serve to strengthen root-hair cell walls and lock them in shape.

Plant cell wall architecture plays an important role in communication with the environment and is at the same time an inert mechanical barrier, which makes it an interesting element in plant-microbe interactions. In legumes, several nodulin genes, including Enod12 (Scheres et al. 1990; Pichon et al. 1992), MtPRP4 (Wilson et al. 1994), and VfNDS-E (Perlick and Pühler 1993), encode putative repetitive proline-rich proteins that are members of the extensin superfamily of cell wall proteins (Kieliszewski and Lamport 1994) and are therefore important for the cell wall structure. Expression of these genes is induced by rhizobia and correlates with the morphogenesis of nodule development. In contrast, transcript levels of the genes ext 3 , ext 127 , and ext 26 decrease in $V$. unguiculata root hairs as soon as 1 day after inoculation, a time when root-hair deformation is apparent (Krause and Broughton 1992). This differential expression of ext3, ext127, and ext26 appears to be part of the general restructuring of plant cell wall architecture in response to Rhizobium (Journet et al. 1994; Pichon et al. 1992; Wilson et al. 1994), which facilitates localized cell wall degradation, leading to a penetration of symbiotic bacteria into the host.

Interestingly, the mutant strain NGR $\triangle \operatorname{nod} A B C$, which can receive signals from the plant but which does not produce Nod factors, also reduced levels of all three extensin-like transcripts. The reduction was less dramatic than that of the wildtype bacterium, suggesting that Nod factors are necessary but not sufficient for a complete response. One possible interpretation of this data is that other, as yet unidentified, bacterial substance(s) exist that act as regulator(s) of extensin expression. Inoculation with NGR $\Delta$ nodD1 (in which molecular communication between the two symbiotic partners is blocked, while this mutant does not perceive the plant signal and therefore does not synthesize bacterial signals) induced gene expression of extensins, suggesting that the second signal might be nodD dependent. NodNGR[Ac] factors only affected expression of ext 3 , perhaps indicating that expression of ext 26 and ext 127 is under the control of different Nod factors or another signal. Further investigation with extensin-promotergusA fusions will provide a more complete picture of the molecular signals involved in regulation of the expression of these root-hair-specific proteins.

\section{MATERIALS AND METHODS}

\section{Plant manipulations.}

Seeds of V. unguiculata (L.) Walp. 'Red Caloona' (purchased from Rawling Seeds, Orpington, Kent, England), were surface sterilized and germinated as described by Krause and Broughton (1992). Two days after sowing, bacterial inoculum or purified Nod factors (1 ml per 35 plants) were sprayed on the seedlings. Rhizobial strains were grown as described by Krause and Broughton (1992). A stock solution of purified NodNGR[Ac] was diluted in sterile water to $10^{-7}$ or $5 \times 10^{-6}$ M. Sterile water was used as a control.

Root hairs were harvested from batches of 1,000 seedlings

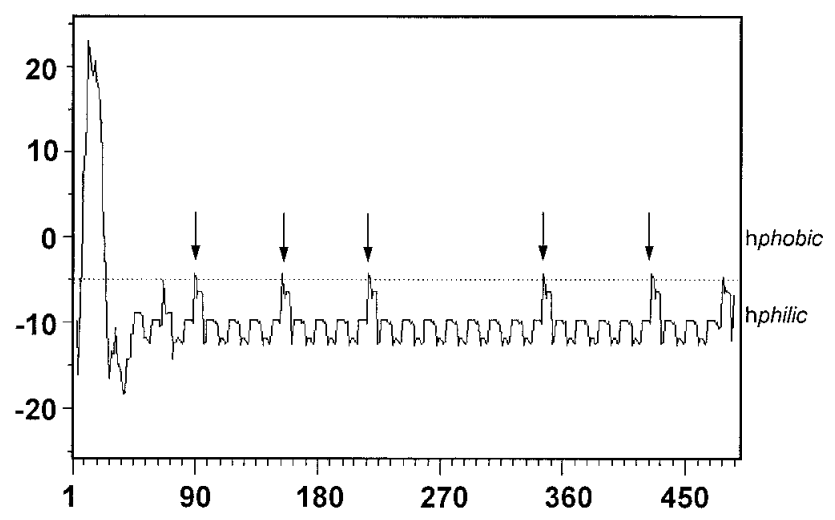

Fig. 6. Hydropathic profile of Vigna unguiculata proextensin corresponding to Ext26G. The hydropathic plot was constructed according to Kyte and Doolittle (1982) with a window of seven amino acids. Repetitive motifs with changes of tyrosine to valine are marked with an arrow. 
1 day after treatment as described by Röhm and Werner (1987). Root-hair preparations harvested this way were virtually free of contaminating pieces of root, cortex, epidermis, and root-cap cells (Krause and Broughton 1992). Young leaves, young seed pods, flower buds, and 5-week-old nodules were collected from plants inoculated with NGR234 and grown in Magenta jars (Lewin et al. 1990). Harvested tissues were immediately placed into liquid nitrogen and kept at $-70^{\circ} \mathrm{C}$ until needed.

\section{DNA and RNA extractions.}

V. unguiculata genomic DNA was extracted from $20 \mathrm{~g}$ of leaves by the method of Schwarz-Sommer et al. (1984). All other recombinant DNA methods were performed according to Sambrook et al. (1989).

Total cellular RNA was extracted from plant material as described by Chandler et al. (1983). RNA was finally resuspended in formamide and kept at $-70^{\circ} \mathrm{C}$ until needed. For expression studies, $10 \mu \mathrm{g}$ of each RNA was separated on $1.2 \%$ denaturing agarose gel containing $8 \%$ formamide, and subsequently transferred to Nylon membranes (Schleicher and Schuell, Dassel, Germany). To confirm amounts and integrity of ribosomal RNA, filters were stained with methylene blue (Sambrook et al. 1989). Densitometric analysis (QuantiScan, Biosoft, Cambridge, UK) of the stained filters was used to verify equal loading.

For Northern and Southern blots, randomly labeled, purified cDNA fragments were prepared with $\left[\alpha^{32} \mathrm{P}\right] \mathrm{dCTP}$ (Amersham International plc, Buckinghamshire, UK). Hybridizations were performed at $42^{\circ} \mathrm{C}$, in the presence of $50 \%$ formamide (Sambrook et al. 1989). Washing was performed at $72^{\circ} \mathrm{C}$, the filters were rinsed twice with $2 \times \mathrm{SSC}(1 \times \mathrm{SSC}$ is $0.15 \mathrm{M} \mathrm{NaCl}$ plus 0. $015 \mathrm{M}$ sodium citrate), $0.1 \%$ (wt/vol) sodium dodecyl sulfate (SDS) for $15 \mathrm{~min}$, and twice with $0.1 \times \mathrm{SSC}, 0.1 \%$ SDS (wt/ vol). Densitometric analysis of hybridization signals was used to calculate the relative amounts of transcripts.

\section{Genomic library construction and screening.}

Purified genomic DNA was partially digested with $\mathrm{MboI}$ and fragments of 15 to $20 \mathrm{~kb}$ were ligated into the BamHI sites of $\lambda$ DASH II replacement vector (Stratagene, La Jolla, $\mathrm{CA})$. In vitro packaging of the ligation mixture into Gigapack II packaging extracts was performed according to the manufacturer's protocol (Stratagene). The resulting genomic library ( $10^{7}$ recombinant plaques per $\mu \mathrm{g}$ of DNA) was screened with randomly labeled ext 26 as probe.

A total of $5 \times 10^{5}$ recombinant phages were replicated on nitrocellulose filters (BA85, Schleicher and Schuell, Dassel, Germany). Hybridization was performed at $72^{\circ} \mathrm{C}$ for 12 to 15 $\mathrm{h}$, in the presence of $5 \times \mathrm{SSC}, 0.1 \% \mathrm{SDS}(\mathrm{wt} / \mathrm{vol}), 0.02 \%$ ficol (wt/vol), $0.02 \%$ polyvinylpyrolidone (wt/vol), and $10 \mu \mathrm{g}$ of denatured Herring sperm DNA per ml. Filters were washed at $72^{\circ} \mathrm{C}$, first with $2 \times \mathrm{SSC}, 0.1 \%$ SDS (wt/vol), and then with $0.1 \times \mathrm{SSC}, 0.1 \% \mathrm{SDS}(\mathrm{wt} / \mathrm{vol})$ for $25 \mathrm{~min}$.

\section{Sequencing.}

As the entire insert of the phage $\lambda \mathrm{G} 2$ proved to be impossible to subclone, two fragments, one hybridizing to the $5^{\prime}$ part of ext 26, the other to the $3^{\prime}$ part, were subcloned into pRK7813 and pUC18 (pH1R and p1450, respectively). Either clone-specific primers or exonuclease III-derived subclones
(Henikoff 1987) were used to sequence the plasmid templates by the dideoxy-chain termination method on plasmid templates (Sequenase II, USB, Cleveland, $\mathrm{OH}$ ) and the fmol DNA Sequencing System (Promega Corporation, Madison, WI) on $\lambda$ phage templates. Sequence data were analyzed with PC/Gene (IntelliGenetics, Inc., Mountain View, CA) and the Blast network service (National Center for Biotechnology Information, Bethseda, MA; Altschul et al. 1990; Gish et al. 1993).

\section{ACKNOWLEDGMENTS}

We thank S. Relić and F. Talmont for providing the NodNGR factors, L. T. T. Vo for some of the RNA samples, and B. Relić for help in subcloning Ext26G. We thank K. Seidel and R. Vögeli-Lange for critical reading of the manuscript. This study was supported by the University of Geneva, the Roche Research Foundation, and the Fonds National Suisse de la Récherche Scientifique (Projects 31-30950.91 and 3140714.94).

\section{LITERATURE CITED}

Altschul, S. F., Gish, W., Miller, W., Myers, E. W., and Liptman, D. J. 1990. Basic local alignment search tool. J. Mol. Biol. 215:403-410.

Arsenijević-Maksimović, I., Broughton, W. J., and Krause, A. 1995. Three different cDNAs (GenBank X86029, X86030, X86028) encoding extensin-like proteins from Vigna unguiculata root hairs. Plant Gene Register PGR-048, Plant Physiol. 109:338.

Cassab, G. I., and Varner, J. E. 1988. Cell wall proteins. Annu. Rev. Plant Physiol. Plant Mol. Biol. 39:321-353.

Chandler, P. M., Higgins, T. J. V., Randall, P. J., and Spencer, D. 1983. Regulation of legumin levels in developing pea seeds under conditions of sulfur deficiency. Plant Physiol. 71:47-54.

Chen, C.-G., Mau, S.-L., and Clarke, A. E. 1993. Nucleotide sequence and style-specific expression of a novel proline-rich protein gene from Nicotiana alata. Plant Mol. Biol. 21:391-395.

Corbin, D. R., Sauer, N., and Lamb, C. J. 1987. Differential regulation of a hydroxyproline-rich glycoprotein gene family in wounded and infected plants. Mol. Cell. Biol. 7:4337-4344.

Cormack, R. G. H. 1962. Development of root hairs in angiosperms. Bot. Rev. 28:446-464.

Dart, P. 1977. Infection and development of leguminous nodules. Pages 367-472 in: A Treatise on Dinitrogen Fixation, Sect. III. R. W. F. Hardy and W. S. Silver, eds. Cambridge University Press, London.

Fellay, R., Rochepeau, P., Relić, B., and Broughton, W. J. 1995. Signals to and emanating from Rhizobium largely control symbiotic specificity. Pages 199-220 in: Pathogenesis and Host Specificity in Plant Diseases. Histopathological, Biochemical, Genetic and Molecular Bases, Vol. 1: Prokaryotes. U. S. Singh, R. P. Singh, and K. Kohmoto, eds. Pergamon/Elsevier Science Ltd., Oxford.

Franssen, H., Mylona, P., Pawlowski, K., Van de Sande, K., Heidstra, R., Geurts, R., Kozik, A., Matvienko, M., Yang W. C., Hadri, AZ-E., Martinez-Abarca, F., and Bisseling, T. 1995. Plant genes involved in root-nodule development on legumes. Philos. Trans. R. Soc. London B 350:101-107.

Franssen, H. J., Nap, J.-P., and Bisseling, T. 1992. Nodulins in root nodule development. Pages 598-624 in: Biological Nitrogen Fixation. G. Stacey, R. H. Burrris, and H. J. Evans, eds. Chapman and Hall, New York.

Gatehouse, J. A., Bown, D., Evans, I. M., Gatehouse, L. N., Jobes, D., Preston, P., and Croy, R. R. 1987. Sequence of the seed lectin gene from pea (Pisum sativum L.). Nucleic Acids Res. 15:7642.

Gish, W., and States, D. J. 1993. Identification of protein coding regions by database similarity search. Nat. Genet. 3:266-272.

Goldman, M. H., Pezzotti, M., Seurinck, J., and Mariani, C. 1992. Developmental expression of tobacco pistil-specific genes encoding novel extensin-like proteins. Plant Cell 4:1041-1051.

Granell, A., Peretó, J. G., Schindler, U., and Cashmore, A. R. 1992. Nuclear factors binding to the extensin promoter exhibit differential activity in carrot protoplasts and cells. Plant Mol. Biol. 18:739-748.

Henikoff, S. 1987. Unidirectional digestion with exonuclease III in DNA 
sequence analysis. Methods Enzymol. 155:156-167.

Holdsworth, M. J., and Laties, G. G. 1989. Site-specific binding of a nuclear factor to the carrot extensin gene is influenced by both ethylene and wounding. Planta 179:17-23.

Journet, E. P., Pichon, M., Dedieu, A., de Billy, F., Truchet, G., and Barker, D. G. 1994. Rhizobium meliloti Nod factors elicit cell-specific transcription of the Enod12 gene in transgenic alfalfa. Plant J. 6:241249.

Kieliszewski, M. J., and Lamport, D. T. 1994. Extensin: Repetitive motifs, functional sites, post-translational codes, and phylogeny. Plant J. 5:157-172.

Kijne, J. W. 1992. The Rhizobium infection process. Pages 349-398 in: Biological Nitrogen Fixation, G. Stacey, R. H. Burris, and H. J. Evans, eds. Chapman and Hall, New York.

Krause, A., and Broughton, W. J. 1992. Proteins associated with roothair deformation and nodule initiation in Vigna unguiculata. Mol. Plant-Microbe Interact. 5:96-103.

Krause, A., Sigrist, C. J. A., Dehning, I., Sommer, H., and Broughton W. J. 1994. Accumulation of transcripts encoding a lipid transfer-like protein during deformation of nodulation-competent Vigna unguiculata root hairs. Mol. Plant-Microbe Interact. 7:411-418.

Kyte, J., and Doolittle, R. F. 1982. A simple method for displaying the hydropathic character of a protein. J. Mol. Biol. 157:105-132.

Lewin, A., Cervantes, E., Wong, C.-H., and Broughton W. J. 1990. nodSU, two new nod genes of the broad host range Rhizobium strain NGR234 encode host-specific nodulation of the tropical tree Leucaena leucocephala. Mol. Plant-Microbe Interact. 3:317-326.

Messing, J., Geraghty, D., Heidecker, G., Hu, N.-T., Kridl, J., and Rubenstein, I. 1983. Plant gene structure. Pages 211-227 in: Genetic Engineering of Plants: An Agricultural Perspective, T. Kosuge, C. P. Meredith, and A. Hollaender, eds. Plenum Press, New York.

Perlick, A. M., and Pühler, A. 1993. A survey of transcripts expressed specifically in root nodules of broadbean (Vicia faba L.). Plant Mol. Biol. 22:957-970.

Pichon, M., Journet, E.-P., Dedieu, A., de Billy, F., Truchet, G., and Barker D. G. 1992. Rhizobium meliloti elicits transient expression of the early nodulin gene ENOD12 in the differentiating root epidermis of transgenic alfalfa. Plant Cell 4:1199-1211.

Relić, B., Perret, X., Estrada-Garcia, M. T., Kopcinska, J., Golinowski, W., Krishnan, H. B., Pueppke, S. G., and Broughton, W. J. 1994. Nodfactors of Rhizobium are a key to the legume door. Mol. Microbiol. 13:171-178.

Ridge, R. W. 1988. Freeze-substitution improves the ultrastructural preservation of legume root hairs. Bot. Mag. 101:427-441.

Röhm, M., and Werner, D. 1987. Isolation of root hairs from seedlings of Pisum sativum. Identification of root hair specific proteins by in situ labeling. Physiol. Plant. 69:129-136.
Rost, B., and Sander, C. 1993. Prediction of protein secondary structure at better than 70\% accuracy. J. Mol. Biol. 232:584-599.

Rost, B., and Sander, C. 1994. Combining evolutionary information and neural networks to predict protein secondary structure. Proteins 19 55-72.

Ruiz-Avila, L., Burgess, S. R., Stiefel, V., Ludevid, M. D., and Puigdomenèch, P. 1992. Accumulation of cell wall hydroxyproline-rich glycoprotein mRNA is an early event in maize embryo cell differentiation. Proc. Natl. Acad. Sci. USA 89:2414-2418.

Sambrook, J., Fritsch, E. F., and Maniatis, T. A. 1989. Molecular Cloning: A Laboratory Manual. 2nd ed. Cold Spring Harbor Laboratory, Cold Spring Harbor, NY.

Scheres, B., van de Wiel, C., Zalensky, A., Horvath, B., Spaink, H., van Eck, H., Zwartkruis, F., Wolters, A.-M., Gloudemans, T., van Kammen, A., and Bisseling, T. 1990. The Enod 12 gene product is involved in the infection process during the pea-Rhizobium interaction. Cell 60:281-294

Schultze, M., Kondorosi, E., Ratet, P., Buiré, M., and Kondorosi, A. 1994. Cell and molecular biology of Rhizobium-plant interactions. Int. Rev. Cytol. 156:1-75.

Schwarz-Sommer, Z., Gier, A., Klösgen, R. B., Wienand, U., Peterson, P. A., and Saedler, H. 1984. The Spm (En) transposable element controls the excision of a 2-kb insert at the wx-m8 allele of Zea mays. EMBO J. 3:1021-1028.

Showalter, A. M., Butt, A. D., and Kim, S. 1992. Molecular details of tomato extensin and glycine-rich protein gene expression. Plant Mol. Biol. 19:205-215.

Smallwood, M., Beven, A., Donovan, N., Neill, S. J., Peart, J., Roberts, K., and Knox, J. P. 1994. Localization of cell wall proteins in relation to the developmental anatomy of the carrot root apex. Plant J. 5:237246

Vaucheret, H., Vincentz, M., Kronenberger, J., Caboche, M., and Rouzé, P. 1989. Molecular cloning and characterization of the two homologous genes coding for nitrate reductase in tobacco. Mol. Gen. Genet. 216:10-15.

von Heijne, G. 1986. A new method for predicting signal sequence cleavage sites. Nucleic Acids Res. 14:4683-4690.

Wilson, R. C., Long, F., Maruoka, E. M., and Cooper, J. B. 1994. A new proline-rich early nodulin from Medicago truncatula is highly expressed in nodule meristematic cells. Plant Cell 6:1265-1275.

Wycoff, K. L., Powell, P. A., Gonzales, R. A., Corbin, D. R., Lamb, C. and Dixon, R. A. 1995. Stress activation of a bean (Phaseolus vulgaris L.) hydroxyproline-rich glycoprotein promoter is superimposed on a pattern of tissue-specific developmental expression. Plant Physiol. 109:41-52.

Ye, Z.-H., and Varner, J. E. 1991. Tissue-specific expression of cell wall proteins in developing soybean tissues. Plant Cell 3:23-37. 